\title{
Oral: Vaginal Misoprostol: Which route for induction of term labor?
}

Ratna Khatri (Adhikari), Jyoti Sharma, Archana Amatya

Maj. Dept of Obstetrics/Gynecology, Army Hospital

\begin{abstract}
Aim: To compare the effectiveness of oral misoprostol with vaginal misoprostol for induction of labour at or more than 40 weeks of pregnancy.

Method: Study design: Prospective comparative study. Duration: March 2005 to February 2006 (12 months)in the Dept of Obs/Gyn, TU Teaching Hospital, Kathmandu. Methods: Hundred nullipara (primi or gravida 2 with 1 spontaneous or induced abortion $\leq 12$ gestational weeks) in a singleton pregnancy $\geq 40$ but with Bishop's score $\leq 4$ were induced equally with either oral (100 mgm) Group A or vaginal (25mcg) Group B: were administered 4 hourly up to maximum of 6 doses. Primary outcome measures: duration of induction to active stage of labour or delivery, spontaneous rupture of membrane (SROM), meconium stained liquor (MSL), caesarean and neonatal morbidity with respect to Apgar score were assessed.
\end{abstract}

Results: In vaginal 33 oral 17 had SROM with higher incidence of MSL (60\% versus 12\%) and higher caesarean 15\%: 4\%. Even there was > fetal distress 11/15: 2/7 group B/, which was statistically significant. No significant difference was noted in the pre induction cervical score, number of doses, induction to active stage of labour, induction to delivery time, use of oxytocin, failed induction and Apgar scores.

Conclusion: Oral misoprostol found to be associated with less SROM, meconium stained liquor and vaginal birth and comparatively less neonatal care unit admissions outweighs its advantages over the vaginal misopristol, although either route were equally proven to be effective for inducing labour in women with unfavourable cervix (Bishop's score $\leq 4)$ at term pregnancy.

\section{Introduction}

Labour is artificially induced if continuation of pregnancy is risk to mother, baby or both and the rate of induced labour as high as $20 \% .{ }^{1}$ However successful vaginal delivery depends on preinduction cervical condition and when Bishop's score is less than 5 , often there is increased risk of prolonged labour, febrile morbidity and most important, a high caesarean delivery rate. In order to improve cervical score and induce myometrial contractility, prostaglandins in various forms and preparations have been used. Misoprostol available in tablet form is a synthetic 15-deoxy -16 hydroxy -16 methyl analogue of naturally occurring prostaglandin $\mathrm{E}_{1}$ popular for stability at room temperature. ${ }^{2-5}$ While dinoprostone $\mathrm{E}_{2}$ analogue is marketed as intracervical gel and needs to be refrigerated to maintain its potency.

Based on meta-analysis, misoprostol has been found to be more effective than prostaglandin $\mathrm{E}_{2}$ for inducing labour with fewer caesarean section rate. ${ }^{6}$ It stimulates uterine contractions acting on EP-2/ EP-3 prostanoid receptors. Their minimal effect on cardiovascular and bronchial tree smooth muscle and it's metabolization by fatty acid oxidizing system found in organs throughout the body pronounces its safety in hypertensive and hepatic dysfunction and renal impairment. ${ }^{7}$ Misoprostol is not suitable for parenteral use because of its rapid degradation in the blood but has been now used sublingually, orally or vaginally. ${ }^{8}$ In Tribhuvan University Teaching Hospital, dinoprostone intracervical gel is being used extensively

\section{Corresspondence}

Dr Ratna Khatri

Maj. Dept of Obstetrics/Gynecology

Army Hospital, Chhawni.

Email:ratnakhatry@gmail.com 
for induction of labour which lately has been replaced by intravaginal prostaglandin because of lower price and ease of application. This paper aims to compare if oral misoprostol in doses of $100 \mathrm{mcg}$ carries more potential benefit effectively over $25 \mathrm{mcg}$ vaginal analogues for induction of labour at or more than 40 weeks of pregnancy.

\section{Methods}

Prospective comparative study conducted during the period of March 2005 to February 2006 (12 months) at the Department of Obstetrics and Gynaecology, Tribhuvan University Teaching Hospital, Institute of Medicine, Kathmandu, Nepal. A total of 100 nullipara (with or without history of one spontaneous or induced abortion $<12$ weeks) at or more than 40 weeks of gestation with singleton pregnancy in vertex presentation with normal fetal heart rate and initial Bishop's score d" 4 were included. Whereas those with known allergy to prostaglandins, premature uterine contraction or, in labour, rupture of membrane, foetal distress, cephalopelvic disproportion, malpresentation, scarred uterus medical disorders: cardiac disease, asthma, glaucoma, hypertension, and thromboembolism were excluded.

Purposive sampling technique wherein 50 each envelopes were labelled A for oral and B for intravaginal misoprostol. Women were blindly asked to select one envelope and grouped accordingly. Premedication like oral anti-emetics were used 15 minutes before administration of oral misoprostol to reduce nausea and vomiting.

Misoprostol tablet in 100 microgram dose for oral (Grp A) who were instructed not to take any food for the next $1 / 2$ an hour to enhance drug absorption). For Group
B vaginal application (posterior fornix), the dose was 25 microgram of misoprostol. Maximum of six doses were allowed in either route which was repeated every 4 hourly after vaginal examination, so that the drug could be withheld till the -Bishop's score was $>4$, spontaneous rupture of membrane or active labour. Despite the maximum 6 doses, if there was no change in cervical score, categorization of failed induction was made. Time from induction to onset of active stage of labour was noted. Uterine hyperstimulation were given analgesics but in case of persistent hyperstimulation further doses of misoprostol were withheld. Whenever active labour (> $4 \mathrm{~cm}$ os dilatation) was reached surgical amniotomy and oxytocin augmentation were followed. Incidence of adverse effects like nausea, vomiting, diarrhoea, fever, hyperstimulation ( $>5$ contractions in 10 minutes and uterine contraction lasting $>90$ seconds) were noted. Patients under study were not given epidosin and buscopan. Meconium stain (mild, moderate or thick) was noted. Neonatal outcomes were measured in terms of Apgar score in 1 and 5 minutes, admission to neonatal care unit.

\section{Results}

During the study period, total number of deliveries was 3657: [Vaginal (77.18\%) and caesarean section rate was $(21.71 \%)$ ]. For various indications like post dated pregnancies, less foetal movement, pregnancy induced hypertension, oligohydramnios and $\mathrm{Rh}$ incompatibility; many women were induced 445 $(11.66 \%)\{330 / 445$ with prostaglandins [misoprostol (146) and dinoprostone (184)] rest by oxytocin (115)\}.

The maximum number of women induced were between the ages of 20-24 years in both the groups (54\% and $64 \%$ respectively), followed by the ages 25-29 years. Mean maternal age was $23.76 \pm 3.04$ and $22.80 \pm 3.52$;

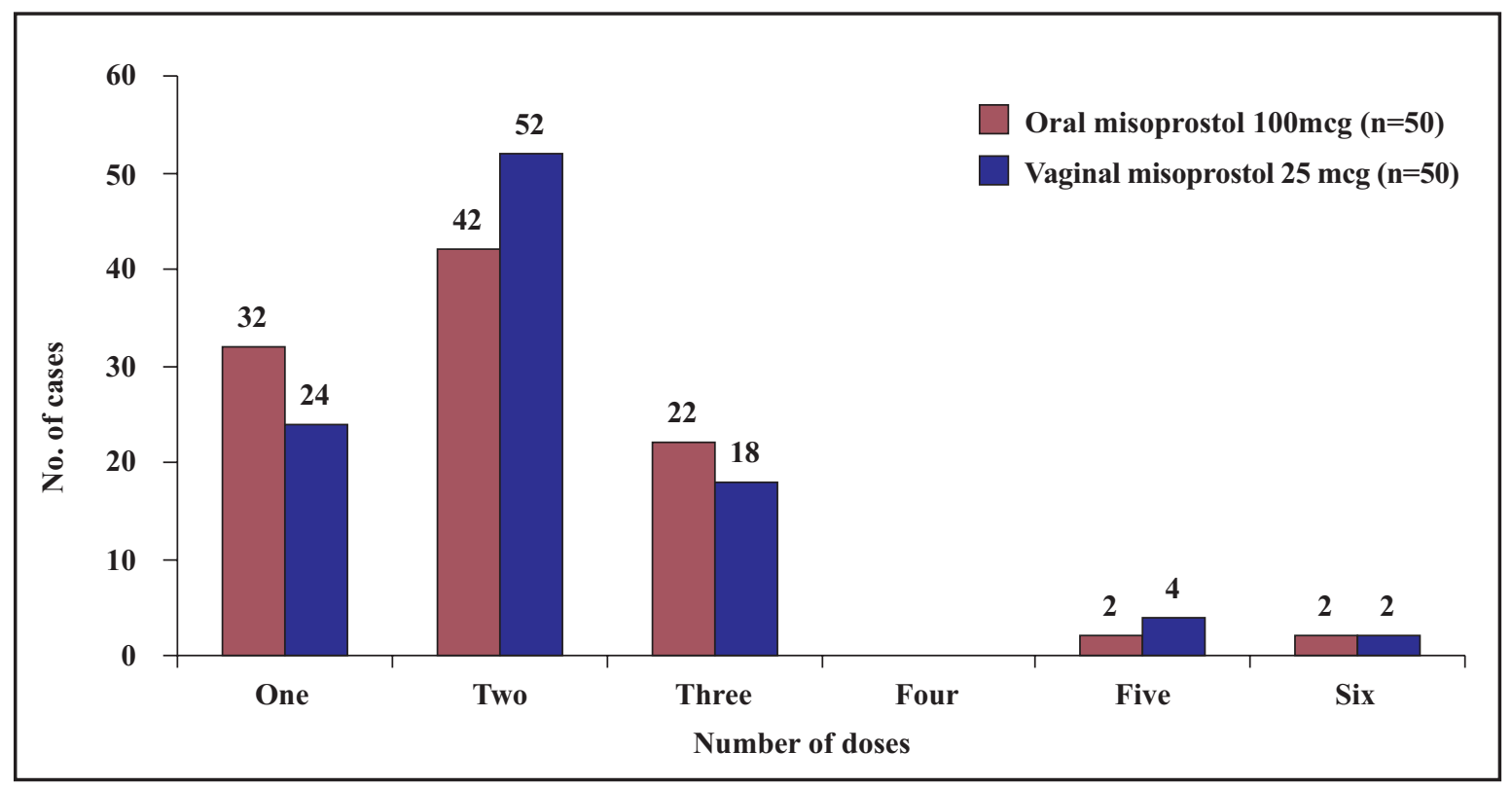

Fig 1. Number of doses required to achieve Bishop's score more than 4 
Mean gestational age (GA) in weeks $40.87 \pm 0.47$ and $40.87 \pm 0.38$ and preinduction cervical score for Grp A and $\mathrm{B}$ was 2.70 and 2.62 respectively.

Out of 100 women, 78 had vaginal delivery whereas 22 underwent caesarean section.

Failure to achieve cervical ripening even after 6 doses of misoprostol was found in one woman in each group $2 / 100(2 \%)$. (Fig 1). One to three doses were good enough to produce desired cervical responses or Bishop's score $>4$ in both the groups $98 \%$ for group A and $94 \%$ for Grp B, thereafter the responses to drug decreased. Maximum response was seen after 2 doses in oral Grp A 21(42\%) or vaginal misoprostol Grp B $26(52 \%)$. However the doses required to achieve Bishop's score more than 4 was statistically not significant between oral and vaginal misoprostol groups. Need for oxytocin was equal in both groups $(n=31)$, whereas equal number of cases did not further need augmentation $(\mathrm{n}=19)$.

Comparing the two groups (Fig 2), although the mean time taken for induction to active stage of labour in the oral group was 1 hour more than the vaginal group, it was statistically not significant. Active stage of labour in Group A: 2-17 hours, mean 9.4 hour with SD 3.6. For Group B, it was in range of $0.5-20 \mathrm{~h}$, mean $8.38 \mathrm{~h}$ with SD $4.93 \mathrm{~h}$. Induction to delivery was $5.47-29 \mathrm{~h}$, (mean 15.5) with SD 4.49 for Grp A and 6.5-28 (mean 15.03) with SD of 6.08 respectively.

Only 17 out of 50 women had spontaneous rupture of membrane in the oral misoprostol group as compared to 33 women in the vaginal misoprostol group. SROM occurred more following second dose of administration in both the groups. (Table1)
Table I. Misoprostol: Number of doses and SROM

\begin{tabular}{|l|l|l|c|}
\hline \multirow{2}{*}{$\begin{array}{c}\text { Number } \\
\text { doses }\end{array}$} & \multicolumn{3}{|c|}{ SROM } \\
\cline { 2 - 4 } & \multicolumn{2}{|c|}{ Spontaneous rupture of membrane. } \\
\cline { 2 - 4 } & Group A & Group B & $p$ value \\
\hline 1 & 4 & 8 & 0.36 \\
2 & 9 & 18 & 0.07 \\
3 & 3 & 4 & 0.66 \\
4 & 0 & 0 & \\
5 & 0 & 2 & 0.40 \\
6 & 1 & 1 & \\
Total & $17(34 \%)$ & $33(66 \%)$ & 0.001 \\
\hline
\end{tabular}

Vaginal misoprostol induction had significantly higher meconium stained liquor $30(60 \%)$ as compared to only $6(12 \%)$ in the oral misoprostol group bearing statistical significance (0.001). Meconium stain was mild, 6: 0/6; moderate $15: 4 / 11$ or thick $15: 2 / 13$ in both A/B Grps. Meconium staining was found within (2: 17) or above (4: 13) 40 weeks of GA or in Grp A:B respectively (Table $2)$. For the same gestational age meconium stained liquor was significantly higher in vaginally induced misoprostol group 30 verus 6 in oral (p 0.001). In Grp A (oral misoprostol), 43 delivered vaginally (one had ventouse delivery and 7 underwent caesarean. In vaginal misoprostol group, 35 delivered vaginal including equal number of ventouse delivery (1). The indication of ventouse was prolonged second stage of labour in oral group and foetal distress with moderate meconium stained liquor in the vaginal group. Caesarean in Grp B compared to Grp A was double i.e. 15 having statistical significance $(p=0.05)$. The

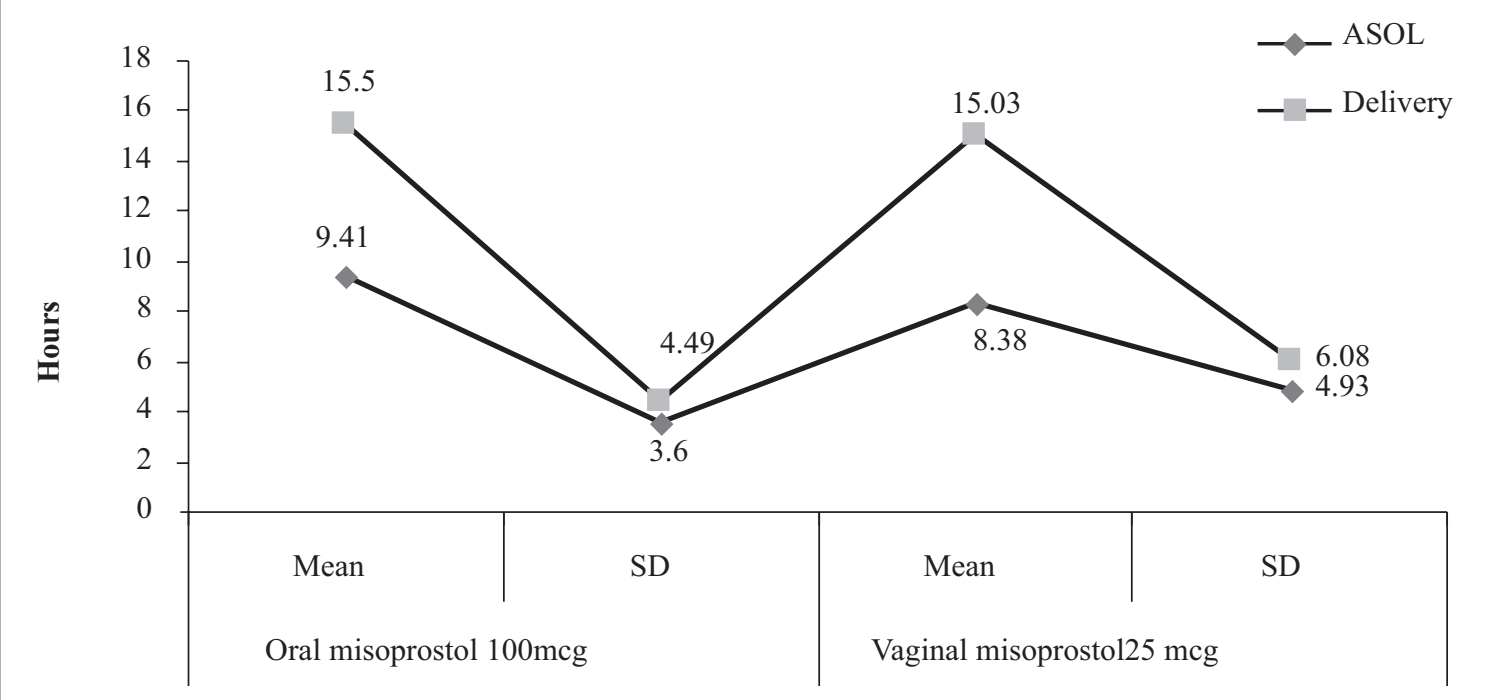

Fig 2. Interval between induction to active stage of labour or delivery in oral and vaginal misoprostol. 
Table 2. Meconium stained liquor

\begin{tabular}{|l|l|c|c|c|}
\hline \multicolumn{2}{|c|}{ Meconium stained liquor } & Group A & Group B & $p$ value \\
\hline G A (in weeks) & $40-40+6$ & 2 & 17 & 0.0004 \\
& 341 & 4 & 13 & 0.03 \\
& Total & 6 & 30 & 0.001 \\
\hline \multirow{2}{*}{ MSL } & Mild & 0 & 6 & 0.493 \\
& Moderate & 4 & 11 & 0.087 \\
& Thick & 2 & $30(60 \%)$ & 0.026 \\
& Total & $6(12 \%)$ & 0.001 \\
\hline
\end{tabular}

Table 3. Mode of delivery and labour outcome

\begin{tabular}{|c|c|c|c|c|}
\hline \multirow{2}{*}{\multicolumn{2}{|c|}{ Mode of delivery }} & \multicolumn{2}{|c|}{ misoprostol } & \multirow{3}{*}{$\begin{array}{l}p \text { value } \\
0.06\end{array}$} \\
\hline & & \multirow{3}{*}{$\begin{array}{c}\begin{array}{c}\text { Group A } \\
\text { oral 100mcg } \\
(\mathrm{n}=50)\end{array} \\
42(84 \%) \\
1(2 \%)\end{array}$} & \multirow{3}{*}{$\begin{array}{c}\text { Group B } \\
\begin{array}{c}\text { Vaginal 25mcg } \\
(\mathrm{n}=50)\end{array} \\
34(68 \%) \\
1(2 \%)\end{array}$} & \\
\hline Vaginal & SVD & & & \\
\hline & Vacuum & & & 1.0 \\
\hline $\mathrm{CS}$ & LSCS & $7(14 \%)$ & $15(30 \%)$ & 0.05 \\
\hline \multirow[t]{4}{*}{ Indication CS } & Foetal distress & 2 & 11 & 0.05 \\
\hline & NP0L & 4 & 0 & 0.005 \\
\hline & Thick MSL in ASOL & 0 & 3 & 0.52 \\
\hline & Failed induction & 1 & 1 & 1.0 \\
\hline
\end{tabular}

Table 4. Labour events and perinatal outcome in oral and vaginal misoprostol.

\begin{tabular}{|c|c|c|c|c|c|}
\hline \multicolumn{3}{|c|}{ Events in labour and perinatal outcome } & $\begin{array}{c}\text { Group A } \\
\text { misoprostol } \\
\text { 100mcg oral }\end{array}$ & $\begin{array}{c}\text { Group B } \\
\text { misoprostol } \\
\text { 25mcg vaginal }\end{array}$ & $p$ value \\
\hline \multicolumn{3}{|c|}{ Foetal distress } & $2(4 \%)$ & $11(22 \%)$ & 0.02 \\
\hline \multirow[t]{2}{*}{ Apgar score } & $1 \min$ & $\begin{array}{l}<6 \\
>6\end{array}$ & $\begin{array}{l}6(12 \%) \\
44(88 \%)\end{array}$ & $\begin{array}{l}11(22 \%) \\
39(78 \%)\end{array}$ & 0.183 \\
\hline & $5 \mathrm{~min}$ & $\begin{array}{l}<6 \\
>6\end{array}$ & $\begin{array}{l}0 \\
50(100 \%)\end{array}$ & $\begin{array}{l}2(4 \%) \\
48(96 \%)\end{array}$ & 0.495 \\
\hline \multicolumn{2}{|c|}{ Wt. of baby (kgs) } & $\begin{array}{l}<2.5 \\
>2.5\end{array}$ & $\begin{array}{l}1(2 \%) \\
49(98 \%)\end{array}$ & $\begin{array}{l}1(2 \%) \\
49(98 \%)\end{array}$ & 1.00 \\
\hline \multicolumn{2}{|l|}{ NICU } & $\begin{array}{l}\text { observation } \\
\text { admission }\end{array}$ & $\begin{array}{l}6(12 \%) \\
0\end{array}$ & $\begin{array}{l}20(40 \%) \\
2(4 \%)\end{array}$ & \\
\hline
\end{tabular}


indication for caesarean was foetal distress in 13 (oral (2) and vaginal (11) respectively. Majority of foetal distress in both the group occurred at late first stage and 3 cases in the vaginal group had foetal distress in the early second stage of labour. Other indication was non progression of labour mostly observed with oral misoprostol whereas thick meconium stained liquor was observed in vaginal group.

Significant number of cases (22\%) in the vaginal group had foetal distress and underwent emergency lower segment caesarean section as compared to two cases $(4 \%)$ in the oral group. There was no significant difference in neonatal birth weight and Apgar score at 1 and 5 minutes in both the groups. Transfers to NICU were statistically significant in two groups. In the oral misoprostol group $44(88 \%)$ babies were directly given to mother, $6(12 \%)$ babies were taken to NICU for stomach wash and observation but none of the babies had to be admitted. In the vaginal misoprostol group $28(56 \%)$ babies were handed over to mother, $20(40 \%)$ babies were taken to NICU for stomach wash and observation out of which $2(4 \%)$ cases had to be admitted in NICU. Two cases in the vaginal group had neonatal admission, one for respiratory distress syndrome and another for meconium aspiration syndrome. Both the babies were managed conservatively and discharged on $10^{\text {th }}$ day. The babies who had meconium stained liquor received stomach wash and then were discharged without further complication.

\section{Discussion}

The main concern about elective induction of labour today are focused on maternal and foetal which indirectly imparts more frequent caesarean use as has been demonstrated by this study with $22 \%$ incidence but with bilateral well being of mother and her baby.

Labour induction in the presence of an unfavourable cervix may be prolonged and tedious where prostaglandin has been helpful increasing the inducibility to a success rate at $98 \%$ as obtained from our study.

Studies have suggested that misoprostol tablets placed into the vagina were either superior to or equivalent in efficacy as compared to intracervical prostaglandin $\mathrm{E}_{2}$ gel. ${ }^{9}$ However with vaginal administration of misoprostol intrauterine pressure is viewed to increase in 25 minutes reaching maximum 46 minutes with longer overall duration of drug exposure in contrast oral to preparation where drug is absorbed within 8 minutes attaining peak plasma level in $25 .{ }^{8}$ Therefore interest in oral misoprostol for cervical ripening and labour induction is growing as it is vouched to bring about rapid drug absorption where it is de-esterified to be converted into misoprostol acid, the active metabolite, $90 \%$ bound to serum protein (half life 21 minutes). ${ }^{8}$ Lack of invasiveness, fewer vaginal examinations and lesser chance of the drug being washed away with liquor amnii, makes oral use more acceptable or equally efficacious. ${ }^{10-13}$

Comparing the efficacy of misoprostol used as vaginal and oral route.

Although few reports stated that vaginal route was better with respect to treatment interval and number of required doses Nopdonrattakoon ${ }^{6}$ and Kwon et al. ${ }^{14}$ our study found that oral group was as good as is viewed by Paungmora et al. ${ }^{15}$

Time interval between induction to delivery: Even the mean induction to active stage of labour and to delivery interval was similar thus correlating to Wing et al. ${ }^{16}$ and Shetty et al., ${ }^{17}$ Uludag et al. ${ }^{18}$ Although this was little earlier for oral than vaginal misoprostol 1240845 and $1381 \pm 802$ minutes. ${ }^{16}$ Shetty et al. ${ }^{17}$ found that $74.5 \%$ in the oral group and $72 \%$ in the vaginal group delivered vaginally.

Spontaneous rupture of membrane: Incidence of spontaneous rupture of membrane was significantly higher in the vaginally induced misoprostol group as compared to the oral misoprostol group (66\% and 34\% respectively). Sharing the increased frequency as observed by Nopdonrattakoon $(39.3 \%$ cases in vaginally induced group and only 20.8). ${ }^{6}$ This is attributable 3 times lower bioavailability of the drug in oral misoprostol, where plasma concentration of the drug rises quickly and also falls steeply as compared to vaginal.

Condition of liquor amnii: Regarding the type of liquor, orally induced misoprostol group had more patients with clear liquor $(44 / 50$ ie $88 \%)$ as compared to the vaginally induced group which had only $20 / 50$ ie $40 \%$ women with clear liquor, which was statistically significant. In all the studies vaginal misoprostol had more number of MSL ${ }^{19}$ According to Uludag this was 16.7\%: $5.9 \% .{ }^{18}$ Increased meconium stained liquor in the vaginally induced group could be explained by the fact that vaginally absorbed misoprostol bypasses the hepatic and gastrointestinal metabolism and so achieves a higher concentration in plasma, increased by the cumulative effect following repeated administration of the drug. Higher concentration of the drug in plasma leads to uterine hyperstimulation and tachysystole causing foetal hypoxia, relaxation of the anal sphincter and meconium stained liquor. ${ }^{20}$ But none having tachysystole or hyper stimulation in our study barely explains the fact.

Mode of delivery: Our study showed better vaginal delivery outcome in the orally induced misoprostol group as was seen by Kwon et al. ${ }^{14}$ or Wing et al. ${ }^{16}$ Lower caesarean rate is possible by manipulating the dose and route. ${ }^{21}$

Neonatal outcome: Dodd ${ }^{22}$ et al. and Carlan ${ }^{3}$ et al. also did not find significant differences in adverse maternal and neonatal outcomes like in our study. 


\section{Conclusion}

Misoprostol in either oral or vaginal route have proven to be equally effective for inducing labour in women with unfavourable cervix (Bishop's score <4) at term pregnancy. However occurrence of lesser number of spontaneous rupture of membrane in the beginning of labour, lesser incidence of meconium stained liquor and fewer caesareans with better neonatal outcome in women induced with oral misoprostol, outweighs its advantages over the vaginal misoprostol.

\section{References}

1. Cunnigham FG, Gant NF, Levend KJ, Gilstrap III LC, Hauth JC, Wenstrom KD. Williams Obstetrics: Induction and augmentation of labour. $21^{\text {st }} \mathrm{ed}$. New York: McGraw-Hill; 2003.p.470-81.

2. Jana N, Arora N, Biwas SC. Misoprostol in cervical ripening and Induction of Labour. In: Barik S, Dutta S, Gupta K edited. Misoprostol in Obstetrics and Gynaecology. New Delhi: Jaypee Brothers; 2005. p. 70-80.

3. Carlan SJ, Bouldin S, Blust D, O'Brien WF. Safety and efficacy of misoprostol orally and vaginally: A randomized trial. Obstet Gynecol 2001; 98: 107-12.

4. Nopdonrattakoon L. A comparison between intravaginal and oral misoprostol for labour induction: A randomized controlled trial. J Obstet. Gynaecol Res.2003; 29:87-91.

5. Chang $\mathrm{CH}$, Chang FM. Randomized comparison of misoprostol and dinoprostone for preinduction cervical ripening and labour induction. J Formos Med Assoc. 1997; 96:366-9.

6. Sanchez-Ramos L, Kaunitz AM, Weans RL, Delke I, Gandier FL. Misoprostol for cervical ripening and labour induction: A meta analysis. Obstet Gynaecol 1997; 89:633-42.

7. Gupta K, Chowdhury B. Misoprostol: Introduction. In: Barik S, Dutta S, Gupta K editors. Misoprostol in Obstetrics and Gynaecology. New Delhi: Jaypee Brothers; 2005. p.1-7.

8. Dutta S, Chakravarti S. Misoprostol: Pharmacology. In: Barik S, Dutta S, Gupta K editors. Misoprostol in Obstetrics and Gynaecology. New Delhi: Jaypee Brothers; 2005. p. 8 -15.

9. Chuck FJ, Huffaker BJ. Labour induction with intravaginal misoprostol versus intracervical prostaglandin $\mathrm{E}_{2}$ gel: A randomized comparison. Am J Obstet Gynecol 1995; 173: 1137.

10. Wing DA, Ham D, Paul RH. A comparison of orally administered misoprostol with vaginally administered misoprostol for cervical ripening and labour induction. Am J Obstet Gynaecol 1999; 180(5):1155-60.

11. Ngai SW, To WK, Lao T, Ho PK. Cervical priming with oral misoprostol in pre labour rupture of membranes at term. Obstetrics and Gynecology 1996; 87:923-26.

12. Bennett KA, Butt K, Crane JMG, Hutchens D, young DC. A comparison of oral and vaginal administration of misoprostol for labour induction. Obstet and Gynecol 1998; 92: 481-6.

13. Windrim R, Bennett K, Mundle W, Young DC. Oral administration of misoprostol for labour induction: A randomized controlled trial. Obstetrics and Gynaecol.1997; 89:392-97.14. Kwon JS, Davies GA, Mackenzie VP. A comparison of oral and vaginal misoprostol for induction of labour at term: a randomized trial. BJOG 2001; 108: 23-6.

15. Paungmora N, Herabutya Y, O-Prasertsawat P, Punyavachira P. Comparison of oral and vaginal misoprostol for induction of labour at term: a randomized controlled trial. J Obstet Gynaecol Res. 2004; 30: 358-62.

16. Wing DA, Park MR, Paul RH. A randomized comparison of oral and intravaginal misoprostol for labour induction. Obstetrics \& Gynaecology 2000; 95:905-8.

17. Shetty A, Livingstone I, Acharya S, Rice P, Danielian P, Templeton A.. Oral misoprostol $(100 \mathrm{mcg})$ versus vaginal misoprostol $(25 \mathrm{mcg})$ in term labour induction: a randomized controlled comparison. Acta Obstet Gynecol Scand. 2003; 82(12): 1103-6.

18. Uludag S, Saricali FS, Madazli R, Cepni I. A comparison of oral vaginal misoprostol for induction of labour. Eur J Obstet Gynaecol Reprod Biol. 2005; 122: 57-60.

19. Ghosh S. A comparative study between vaginal misoprostol and dinoprostone for the induction of labour at term (MD Thesis). Tribhuvan University; 2005.

20. Nalini N, Rani U. Role of misoprostol (intravaginal) in cervical ripening and induction of labour. Obs \& Gynae today 2006; 11(5): 258-62.

21. Colon I, Clawson K, Hunter k, Druzin ML, Taslimi MM. Prospective randomized clinical trial of inpatient cervical ripening with stepwise oral misoprostol versus vaginal misoprostol. Am J Obstet Gynecol 2005; 192: 747-52.

22. Dodd JM, Crother CA, Robinson JS. Oral misoprostol for induction of labour at term: randomized controlled trial. BMJ 2006; 332:50913. 